\title{
The Relation between Pre-Procedural Increase in Urinary Albumin Excretion and Changes in Estimated Glomerular Filtration Rate after Coronary Angiography in Diabetic Patients
}

\author{
Magdy Mohamed El Sharkawy ${ }^{1}$, Mohamed Abd El Monem ${ }^{1}$, Ahmed Yehya Ramadan², Lina Essam Khedr*1 \\ Departments of ${ }^{1}$ Internal Medicine and ${ }^{2}$ Cardiology, Faculty of Medicine - Ain Shams University \\ *Corresponding author: Lina Essam Khedr, Mobile: (+20) 01223421925, E-Mail: linakhedr@med.asu.edu.eg
}

\begin{abstract}
Background: Contrast-induced nephropathy (CIN), is an acute impairment in renal function, and typically occurs within 3 days following the exposure to a iodinated contrast medium (CM). It is associated with increased hospital stay and increased morbidity and mortality. Adult patients with diabetes have a higher risk than the general population for developing contrast-induced nephropathy.

Objective: To assess the significance of preprocedural microalbuminuria on renal function changes post coronary angiography.

Patients and methods: The current study included 40 patients all over the age of 18 years, with diabetes mellitus type 1 or type 2, scheduled for coronary angiography with estimated GFR $>60 \mathrm{ml} / \mathrm{min}$.

Results: incidence of contrast-induced nephropathy in this study was $40 \%(\mathrm{n}=16)$ of patients while $60 \%(\mathrm{n}=24)$ did not fit the definition of CIN. There was no statistically significant difference in the age, gender distribution and use of angiotension converting enzyme inhibitors (ACEIs) or diuretics between the cases who developed and who did not develop CIN. The mean albumin creatinine ratio (ACR) in the group with no contrast induced nephropathy was $225.38 \pm 209.53$ which was statistically significantly lower when compared to the cases with contrast-induced nephropathy $(420.43 \pm 348.52)(\mathrm{p}=0.033)$. The mean HbA1c in no contrast-induced nephropathy group was 7.11 \pm 0.64 and in contrast induced nephropathy group it was $9.09 \pm 0.66$, which was significantly higher $(\mathrm{P}>0.001)$. With univariate regression analysis, ACR, HbA1c and number of vessels affected were shown to be risk factors for occurrence of CIN after use of contrast, but with multivariate analysis, both ACR and HbA1c were shown to be risk factors for CIN.
\end{abstract}

Conclusion: An increase in urinary albumin creatinine ratio in itself maybe be a risk factor for development of contrast-induced nephropathy in diabetic patients.

Keywords: Urinary albumin excretion, Estimated glomerular filtration rate, Coronary angiography, Diabetic patients.

\section{INTRODUCTION}

Contrast-induced nephropathy (CIN) is an increasingly common cause of iatrogenic acute kidney injury (AKI) ${ }^{(1)}$ and represents about $12 \%$ of the cases of hospital-acquired AKI ${ }^{(2)}$. Although the risk of renal function impairment associated with radiological procedures is low $(0.6-2.3 \%)$ in the general population patients with cardiovascular disease are more susceptible, with the higher incidence being reported after emergency PCI ${ }^{(3,4)}$.

Although the pathophysiology of CIN is poorly understood, intrarenal vasoconstriction, and direct tubular damage are among the predominant factors contributing in the development of CIN ${ }^{(5)}$. Several groups have documented immediate vasoconstriction and reduction in renal blood flow occurring after administration of contrast medium ${ }^{(6)}$. Exposure of renal tissue to high osmotic radiocontrast agents results in characteristic histopathologic changes called "osmotic nephrosis." (7). Histopathologic features of "osmotic nephrosis" includes focal or diffuse vacuolization of the proximal tubular cells as well as tubular necrosis ${ }^{(8)}$. Risk factors for developing CIN include diabetes with chronic kidney disease (CKD) ${ }^{(5}$, 9). The overall incidence of CIN in patients with type 2 diabetes was $21.5 \%$ in a study by Sany $\boldsymbol{e t}$ al. ${ }^{\left({ }^{(10)}\right.}$ that included 200 patients ${ }^{(10)}$. Evidence suggests that patients in a pre-diabetic state are also at increased risk of CIN especially if they have CKD. Toprak et al. ${ }^{(11)}$ showed that CIN occurred in $20 \%$ of patients with CKD and diabetes and in $11.4 \%$ of patients with CKD and pre-diabetes, versus $5.5 \%$ of patients with CKD but no evidence of diabetes or prediabetes. These findings about the incidence of CIN in diabetic patients are inconsistent which might be due to the existence of different phenotypes of diabetic nephropathy ${ }^{(\mathbf{1 2})}$.

An increase in serum creatinine and, less commonly, oliguria are the major clinical manifestations of contrast nephropathy. In a prospective study, among approximately 40 patients who developed contrast nephropathy, none was oliguric ${ }^{(13)}$. The increased creatinine is generally observed within 24 to 48 hours after contrast exposure and is mild. Creatinine usually starts to decline within three to seven days. Oliguria (if it occurs) occurs immediately after the procedure (13). Other manifestations of acute kidney injury may be present, including hyperkalemia, acidosis and hyperphosphatemia ${ }^{(\mathbf{1 4})}$. The diagnosis of contrastinduced nephropathy is based upon the clinical presentation, including the characteristic rise in serum creatinine concentration beginning with the first 24 to 
48 hours after contrast exposure, and the exclusion of other causes of acute kidney injury ${ }^{(15)}$.

The aime of present work was to assess the significance of preprocedural microalbuminuria on renal function changes post coronary angiography.

\section{PATIENTS AND METHODS}

This prospective study included 40 patients. The study was conducted in Ain Shams University Hospital on patients scheduled for coronary angiography. All patients had an estimated GFR preprocedure over 60 $\mathrm{ml} / \mathrm{min}$ calculated by Modification of Diet in Renal Disease (MDRD) formula and all patients were diabetic (either type 1 or type 2). Patients with primary nephropathies proven by biopsies were excluded. Patients with GFR $<60 \mathrm{ml} / \mathrm{min}$, thyroid disease or allergy to iodinated contrast were excluded from this study. All patients wee subjected to history taking as regards their antidiabetic and other antihypertensive or antiischemic medications. Serum samples for creatinine levels were measured preprocedure (day 0 ), day +2 and +3 . Urinary albumin creatinine ration was measured using early morning urine sample preprocedure. GFR was estimated for all patients using MDRD formula (modification of diet in renal disease).

The patients were divided according to their preprocedural urinary albumin creatinine ratio (ACR) results into 3 groups. Group 1 included patients with pre-procedure urinary albumin creatinine ratio $<30$ $\mathrm{mg} / \mathrm{g}$. Group 2 included patients with pre-procedure albumin creatinine ratio $30-300 \mathrm{mg} / \mathrm{g}$. Group 3 included patients with pre-procedure albumin creatinine ratio > $300 \mathrm{mg} / \mathrm{g}$. Estimated GFR (glomerular filtration rate) calculated using MDRD and serum creatinine were measured at day 2 and 3 (Day +2 and +3$)$ after coronary angiography. Contrastinduced nephropathy was defined as rise of serum creatinine over $25 \%$ from baseline 24 to 72 hours post exposure to contrast media.
Ethical approval and written informed consent:

An approval of the study was obtained from Ain Shams University academic and ethical committee. Every patient signed an informed written consent for acceptance of the operation.

\section{Statistical analysis}

The collected data were coded, processed and analyzed using the SPSS (Statistical Package for Social Sciences) version 22 for Windows ${ }^{\circledR}$ (IBM SPSS Inc, Chicago, IL, USA). Data were tested for normal distribution using the Shapiro Walk test. Qualitative data were represented as frequencies and relative percentages. Chi square test $(\chi 2)$ to calculate difference between two or more groups of qualitative variables. Quantitative data were expressed as mean \pm SD (Standard deviation). Independent samples t-test was used to compare between two independent groups of normally distributed variables (parametric data). $\mathrm{P}$ value $<0.05$ was considered significant.

\section{RESULTS}

This study included 40 diabetic patients who underwent injection of contrast for coronary angiography. Our study population mean age was $55.42 \pm 8.52$ years. It included 27 males and 13 females. $65 \%(\mathrm{n}=26)$ of the population were hypertensive, $55 \%(\mathrm{n}=22)$ were smokers. $57.5 \%(\mathrm{n}=$ 23) had a BMI over 30. 19 patients were receiving metformin at time at presentation, either in combination with insulin or oral hypoglycemics.

9 patients were receiving either ACEIs or ARBs, 16 were receiving diuretics and 16 were receiving beta blockers. According to the results of urinary ACR (albumin creatinine ratio), patients were divided into 3 groups, group $1(\mathrm{n}=7)$ with urinary ACR $<30 \mathrm{mg} / \mathrm{g}$, group $2(\mathrm{n}=19)$ with urinary ACR results from $30-300$ $\mathrm{mg} / \mathrm{g}$ and group $3(\mathrm{n}=14)$ with urinary ACR over 300 $\mathrm{mg} / \mathrm{g}$ (Table 1).

Table (1): Study population demographics and clinical data

\begin{tabular}{|c|c|c|c|c|}
\hline \multirow{2}{*}{ Age (years) } & Min & $\operatorname{Max}$ & Mean & $\mathrm{SD}$ \\
\hline & 40 & 76 & 55.42 & 8.5 \\
\hline \multicolumn{3}{|c|}{ Sex } & & \\
\hline \multicolumn{2}{|c|}{ Males } & 27 & \multicolumn{2}{|c|}{$67.50 \%$} \\
\hline \multicolumn{2}{|c|}{ Females } & 13 & \multicolumn{2}{|c|}{$32.50 \%$} \\
\hline \multicolumn{5}{|c|}{ Clinical data } \\
\hline \multicolumn{2}{|c|}{ HTN } & 26 & \multicolumn{2}{|c|}{$65 \%$} \\
\hline \multicolumn{2}{|c|}{ Smoking } & 22 & \multicolumn{2}{|c|}{$55 \%$} \\
\hline \multicolumn{2}{|c|}{ Obesity } & 23 & \multicolumn{2}{|c|}{$57.50 \%$} \\
\hline \multicolumn{5}{|c|}{ ACR grade $(\mathrm{mg} / \mathrm{g})$} \\
\hline \multicolumn{2}{|c|}{ Grade 1 (below 30) } & 7 & \multicolumn{2}{|c|}{$17.50 \%$} \\
\hline \multirow{2}{*}{\multicolumn{2}{|c|}{$\begin{array}{l}\text { Grade II (30-300) } \\
\text { Grade IU }(>300)\end{array}$}} & 19 & \multicolumn{2}{|c|}{$47.50 \%$} \\
\hline & & 14 & \multicolumn{2}{|c|}{$35 \%$} \\
\hline
\end{tabular}




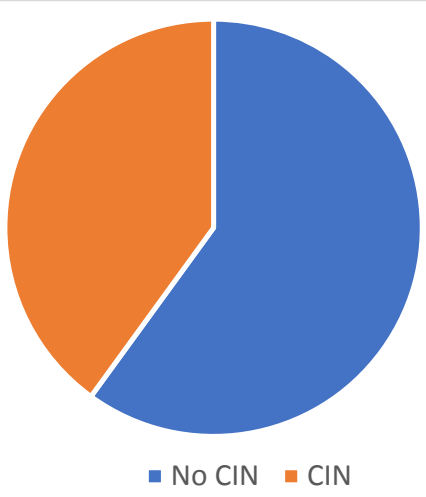

Fig (1): Pie chart for incidence of contrast-induced nephropathy in our study $40 \%(\mathrm{n}=16)$ of patients developed contrast-induced nephropathy post coronary angiography while $60 \%(\mathrm{n}=24)$ did not fit the definition of CIN (Figure 1).

Table (2): The relation between demographics and patients characteristics and the occurrence of CIN.

\begin{tabular}{|c|c|c|c|c|}
\hline & $\begin{array}{l}\text { No contrast induced } \\
\text { nephropathy }(\mathrm{N}=\mathbf{2 6})\end{array}$ & $\begin{array}{l}\text { Contrast induced } \\
\text { nephropathy }(N=14)\end{array}$ & Test of significance & $P$ value \\
\hline Age (years) & $59.92 \pm 7.91$ & $54.5 \pm 9.81$ & $\mathrm{t}=0.499$ & 0.621 \\
\hline \multicolumn{5}{|l|}{ Sex } \\
\hline Males & $17(65.4 \%)$ & $10(71.4 \%)$ & \multirow{2}{*}{$\chi 2=0.151$} & \multirow{2}{*}{0.697} \\
\hline Females & $9(34.6 \%)$ & $4(28.6 \%)$ & & \\
\hline HTN & $17(65.4 \%)$ & $9(64.3 \%)$ & $\chi 2=0.005$ & 0.945 \\
\hline Smoking & $14(53.8 \%)$ & $8(57.1 \%)$ & $\chi 2=0.041$ & 0.842 \\
\hline Obesity & $16(61.5 \%)$ & $7(50 \%)$ & $\chi 2=0.496$ & 0.481 \\
\hline
\end{tabular}

Table (2) showed that the mean age of the cases with no contrast-induced nephropathy was $59.92 \pm 7.91$ and there were 17 males $(65.4 \%)$ and 9 females $(34.6 \%)$ in this group while the mean age in the group with contrastinduced nephropathy was $54.5 \pm 9.81$ years and there were 10 males $(71.4 \%)$ and 4 females $(28.6 \%)$ in this group. There was no statistically significant difference in the age and sex distribution between the cases in the two groups. Regarding the associated chronic disease in the two study groups, there were 17 cases $(65.4 \%)$ and 9 cases $(64.3 \%)$ with HTN in group A and group B respectively. There were $14(53.8 \%)$ and 8 smokers $(57.1 \%)$ in group A and group B respectively. There were 16 obese patients (61.5\%) and 7 obese patients (50\%) in group A and group B respectively. There was no statistically significant difference between the two study groups. Although more patients using metformin and ACEIs had CIN, there was no statistically significant difference within the two groups regarding the use of different drugs (Tables $3 \& 4$ ).

Table (3): Relation between HbA1C and incidence of CIN

\begin{tabular}{|l|l|l|l|l|}
\hline & $\begin{array}{c}\text { No contrast induced } \\
\text { nephropathy } \\
(\mathbf{N}=\mathbf{2 6})\end{array}$ & $\begin{array}{c}\text { Contrast induced } \\
\text { nephropathy } \\
(\mathbf{N}=\mathbf{1 4})\end{array}$ & Test of significance & P value \\
\hline HbA1c $(\%)$ & $7.11 \pm 0.64$ & $9.09 \pm 0.66$ & $\mathrm{t}=-9.273$ & $<0.001^{*}$ \\
\hline
\end{tabular}


Table (4): The effect of patients' medication on development of CIN.

\begin{tabular}{|l|c|c|c|c|}
\hline Drugs & $\begin{array}{c}\text { No contrast induced } \\
\text { nephropathy } \\
(\mathbf{N}=\mathbf{2 6})\end{array}$ & $\begin{array}{c}\text { Contrast induced } \\
\text { nephropathy } \\
(\mathbf{N}=\mathbf{1 4})\end{array}$ & Test of significance & P value \\
\hline Metformin & $11(42.3 \%)$ & $8(57.1 \%)$ & $\chi 2=0.803$ & 0.370 \\
\hline ACEIs & $3(11.5 \%)$ & $3(21.4 \%)$ & $\chi 2=0.698$ & 0.403 \\
\hline ARBs & $2(7.7 \%)$ & $1(7.1 \%)$ & $\chi 2=0.004$ & 0.950 \\
\hline Diuretic & $11(42.3 \%)$ & $5(35.7 \%)$ & $\chi 2=0.165$ & 0.658 \\
\hline CCBs & $5(19.2 \%)$ & $2(14.3 \%)$ & $\chi 2=0.154$ & 0.695 \\
\hline BBs & $9(34.6 \%)$ & $6(42.9 \%)$ & $\chi 2=0.264$ & 0.608 \\
\hline
\end{tabular}

In the group with contrast-induced nephropathy, out of 14 patients only 3 patients had no significant stenosis in their vessels while 6 patients had 1 vessel affected and 5 patients had 2 vessels affected. In the no contrast-induced nephropathy group, single vessel affection was present in 53.8\% $(\mathrm{n}=14)$ of the cases and 2 vessels affection were detected in $15.4 \%$ of the cases $(n=4)$. There was a statistically significant higher number of patients in the CIN group who had multi vessel affection (35.7\%) when compared to those in the non-CIN group (15.4\%).

Table (5): The relation between numbers of coronary vessels affected in coronary angiography and the development of CIN.

\begin{tabular}{|c|c|c|c|}
\hline & \multicolumn{2}{|c|}{ Groups } & \multirow[b]{2}{*}{$\begin{array}{c}\text { Test of } \\
\text { significance }\end{array}$} \\
\hline & $\begin{array}{l}\text { No contrast induced } \\
\text { nephropathy } \\
(\mathbf{N}=\mathbf{2 6})\end{array}$ & $\begin{array}{c}\text { Contrast induced } \\
\text { nephropathy } \\
(\mathbf{N}=14)\end{array}$ & \\
\hline \multicolumn{4}{|l|}{ Vessel state } \\
\hline No vessels affected & $8(30.8 \%)$ & $3(21.4 \%)$ & $\begin{array}{l}\chi 2=2.211 \\
P=0.396\end{array}$ \\
\hline Single vessel affected & $14(53.8 \%)$ & $6(42.9 \%)$ & $\begin{array}{l}\chi 2=2.107 \\
P=0.432\end{array}$ \\
\hline 2 vessels affected & $4(15.4 \%)$ & $5(35.7 \%)$ & $\begin{array}{l}\chi 2=4.664 \\
P=0.031^{*}\end{array}$ \\
\hline
\end{tabular}

The mean ACR in the group with no contrast-induced nephropathy was $225.38 \pm 209.53$, which was statistically significantly lower as compared to the cases with contrast-induced nephropathy $(420.43 \pm 348.52)$. Patients with grade 3 proteinuria ( $\mathrm{UACR}>300 \mathrm{mg}$ ) had higher incidence of contrast-induced nephropathy when compared to patients with grade 1 and grade 2 proteinuria (Table 6). 
Table (6): Association between grade of proteinuria and the development of CIN.

\begin{tabular}{|c|c|c|c|c|}
\hline & $\begin{array}{c}\text { No contrast induced } \\
\text { nephropathy }\end{array}$ & $\begin{array}{c}\text { Contrast induced } \\
\text { nephropathy }\end{array}$ & $\begin{array}{c}\text { Chi square } \\
\text { test }\end{array}$ & P value \\
\hline $\begin{array}{c}\text { Grade } 1 \\
\text { (uACR } 30 \mathrm{mg} / \mathrm{g})\end{array}$ & $5(19.2 \%)$ & $2(14.3 \%)$ & 1.43 & 0.237 \\
\hline $\begin{array}{l}\text { Grade } 2 \\
\text { (uACR } 30-300 \mathrm{mg} / \mathrm{g})\end{array}$ & $15(57.5 \%)$ & $4(28.6 \%)$ & 7.736 & $<0.001$ \\
\hline $\begin{array}{l}\text { Grade } 3 \\
\text { (uACR }>300 \mathrm{mg} / \mathrm{g})\end{array}$ & $6(23.1 \%)$ & $8(57.1 \%)$ & 9.552 & $<0.001$ \\
\hline
\end{tabular}

Table (7): Univariate and multivariate analysis of predictors of CIN ( $\mathrm{n}=14)$

\begin{tabular}{|l|l|l|l|l|}
\hline \multirow{2}{*}{ Variables } & \multirow{2}{*}{$\begin{array}{c}\text { Univariate } \\
\text { analysis }\end{array}$} & \multicolumn{3}{|c|}{ Multivariate analysis } \\
\cline { 4 - 5 } & & OR & 95\% CI for OR & P value \\
\hline Age & 0.686 & & & \\
\hline Sex & 0.772 & & & \\
\hline Serum creatinine before contrast & 0.113 & & & \\
\hline eGFR before contrast & 0.651 & & & \\
\hline CKD grade before contrast & 0.567 & & & \\
\hline ACR & $<0.001^{*}$ & 824 & $273-2.982$ & $043^{*}$ \\
\hline Vessels affected & $0.021^{*}$ & 432 & $286-1.056$ & 132 \\
\hline HbA1c & $0.005^{*}$ & 684 & $064-2.455$ & $045^{*}$ \\
\hline HTN (hypertension) & 0.231 & & & \\
\hline Smoking & 0.338 & & & \\
\hline Obesity & 0.154 & & & \\
\hline
\end{tabular}

With univariate regression analysis, ACR, HbA1c and number of vessels affected were shown to be risk factors for occurrence of CIN after use of contrast, but with multivariate analysis, both ACR and HbAlc were shown to be risk factors for CIN (Table 7). As shown in table (8) and figure (3), the best cutoff point of ACR to predict the occurrence of CIN was more than 160 with $78 \%$ sensitivity, 57\% specificity, 58\% PPV, 80\% NPV and total accuracy of $62 \%$. The AUC was 0.672 with no significant difference $(\mathrm{p}=0.076)$.

Table (8): Analysis of the diagnostic ability of ACR to predict the occurrence of CIN.

\begin{tabular}{|l|l|}
\hline Variable & $A C R$ \\
\hline AUC & 0.672 \\
\hline Cut off point & $>160$ \\
\hline Sensitivity & $78 \%$ \\
\hline Specificity & $57 \%$ \\
\hline PPV & $58 \%$ \\
\hline NPV & $80 \%$ \\
\hline Accuracy & $62 \%$ \\
\hline$P$ & 0.076 \\
\hline
\end{tabular}

AUC: area under the curve. P: probability.significant $p$ value $(<0.05)$.PPV: Positive predictive value. NPV: Negative predictive value. 


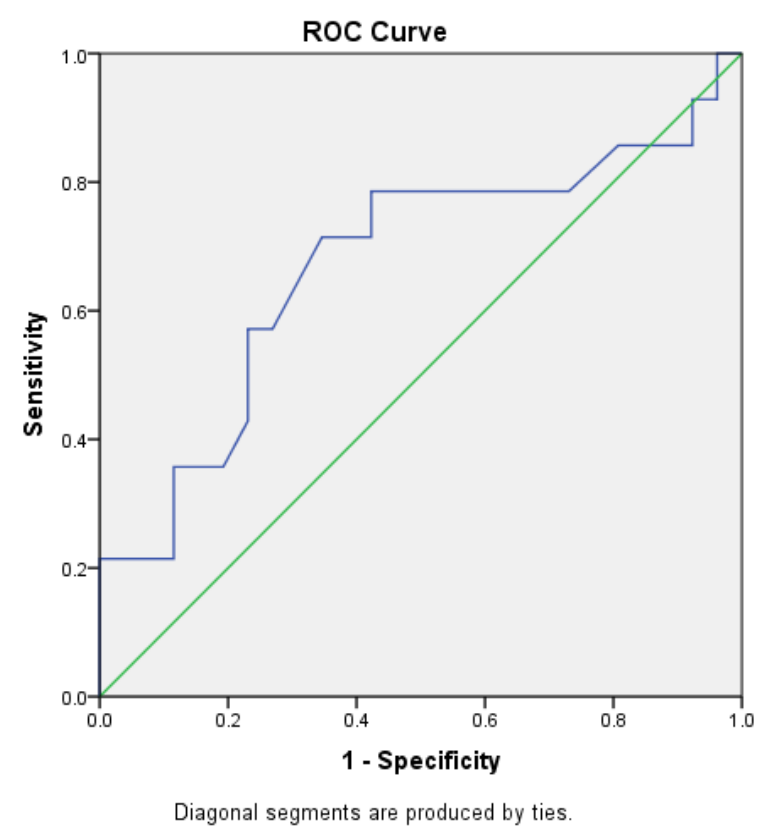

Figure (3): ROC curve for ACR to predict the occurrence of CIN.

\section{DISCUSSION}

Diabetes mellitus is a common chronic disease with high prevalence in Egypt. Contrast-induced nephropathy (CIN) is a common complication of contrast injection with diagnostic and interventional procedures such as coronary angiography. The incidence of CIN is higher among diabetic patients as compared to non-diabetics. Good control of diabetes and follow up of HbA1c can reduce the risk of CIN. Basal albumin creatinine ratio could be used as an early non-invasive marker for early prediction of CIN before its development.

Contrast-induced nephropathy (CIN), is an acute impairment in renal function, and typically occurs within 3 days following the exposure to a contrast medium $(\mathrm{CM}){ }^{(\mathbf{1 6})}$. In the United States, CIN is one of the leading causes of acute kidney injury, accounting for $11-14.5 \%$, and is associated with increased cost, hospital stay, and long-term morbidity and mortality (17). Patients at highest risk for CIN include those with pre-existing renal injury, particularly when it is secondary to diabetic nephropathy (DN) ${ }^{(\mathbf{1 8})}$.

The incidence of CIN in our study was $40 \%$. In the study conducted by Ma et $\boldsymbol{a l} .{ }^{(19)}$ the incidence of CIN was (17.78\%). In one of the major epidemiological study, Tao et al. ${ }^{(20)}$ reported $14.5 \%$ incidence of CIN after coronary intervention but those studies were not on strictly diabetic patients. Moreover, McCullough et al. ${ }^{(21)}$ reported that the CIN rate seems to reach $50 \%$ after contrast exposure in subjects with diabetes and CKD. Sany and his colleagues ${ }^{(10)}$ showed that overall incidence of CIN in type II diabetic patients was $21.5 \%$ (43 out of 200 patients), incidence of CIN in diabetic patients with microalbuminuria was $17 \%$ (17 out of 100 patients), while incidence of CIN in diabetic patients with macroalbuminuria was $26 \%$ (26 out of 100 patients).

It was reported that higher prevalence of CIN was observed in patients with increased age, possibly reflecting the decline in renal function with age. Advanced age is associated with increased vascular stiffness with declined endothelial function (5). However, there was no difference as regards both groups regarding the age in our study. Several drugs are known to affect renal blood flow especially ACEIs and ARBs.

In this study, there was no significant association between the development of contrast-induced nephropathy and the use of different drugs including metformin, ACEIs, angiotensin II receptor blockers (ARBs), diuretics, calcium channel blockers (CCBs) and beta-blockers (BBs). This agrees with Ma and his colleagues ${ }^{(19)}$ who showed that there is no statistically significant difference in the use of different drugs between the cases who developed and who didn't develop CIN except for digoxin and spironolactone, however none of the patients in this study were on either drugs .

Hyperglycemia is a well-known risk factor for endothelial dysfunction. Basile et al. ${ }^{(22)}$ reported that microvascular damage significantly affects the kidney in short and long term. In our study, the mean HbAlc in the group that did not develop contrast-induced nephropathy was significantly lower $(7.11 \pm 0.64)$ than in the contrast-induced nephropathy group (9.09 \pm 0.66) $(\mathrm{P}>0.001)$. Further, poorly controlled blood sugar contributes to endothelial cell dysfunction making the effect of iodinated contrast more pronounced on the kidneys.

Isobe et $\boldsymbol{a l} .{ }^{(23)}$ reported that after adjusting for risk factors, the multivariate logistic regression 
analysis revealed that pre-procedural urinary microalbumin levels and $\mathrm{HbAlc}$ were independent predictors for CIN (OR: 1.030, 95\% CI: 1.020-1.039, $\mathrm{p}=0.008$ ).

In our current study, more patients with multiple diseased vessels in their coronary angiography had contrast-induced nephropathy than those who had no or single vessel affection, which was found to be statistically significant $(p=0.031)$. This agrees with Ma and his colleagues ${ }^{(19)}$ who revealed that multivessel coronary disease in CIN group were significantly higher than that in no CIN group ( $\mathrm{p}<$ $0.005)^{(19)}$. Possibly due to the larger volume of contrast required in such patients to visualize diseased vessels and the worst state of blood vessels as regards atherosclerosis, which might also affect renal as well as coronary vasculature.

An Egyptian study conducted by Sany et al. ${ }^{(10)}$ showed that cases who developed CIN after injection of the dye had higher base line serum creatinine (1.18 \pm 0.19 vs. $1.05 \pm 0.15, \mathrm{p}<0.001)$, and lower creatinine clearance $(78.26 \pm 22.07$ vs. $92.75 \pm 9.27$, p $<0.001)$. In our study, the baseline serum creatinine was lower in the group with no contrast-induced nephropathy $(1.04 \pm 0.2 \mathrm{mg} / \mathrm{dl})$ while in the contrastinduced nephropathy group, serum creatinine pre contrast was $1.12 \pm 0.14 \mathrm{mg} / \mathrm{dl}$ and the estimated GFR was lower. This may be explained by the fact that all patients had GFR over $60 \mathrm{ml} / \mathrm{min}$ before contrast and that the study did not include patients with advanced CKD.

In this study, the mean urinary ACR in the group with contrast-induced nephropathy was significantly higher $(420.43 \pm 348.52 \mathrm{mg} / \mathrm{g})$ as compared to mean urinary ACR in the group that did not develop contrast-induced nephropathy $(225.38 \pm 209.53 \mathrm{mg} / \mathrm{g})$ $(\mathrm{p}=0.033)$. Most patients who developed contrastinduced nephropathy had high degree of proteinuria (urinary ACR $>300 \mathrm{mg} / \mathrm{g})(\mathrm{n}=8)$. This agrees with Ma et al. ${ }^{(19)}$ who found that urinary ACR levels were higher in patients who developed CIN (50\%) as compared to the cases with no CIN (12.84\%) ( $\mathrm{P}<$ 0.001). This also agrees with Sany et al. ${ }^{(10)}$ who reported that cases who developed CIN had higher urinary ACR as compared to the cases who didn't develop CIN (583.4 \pm 471.91 vs. $343.2 \pm 358.8, \mathrm{p}=$ 0.003 ). Since, the development of albuminuria is the first stage of development of diabetic nephropathy and diabetic kidney disease, the presence of albuminuria itself signifies the presence of endothelial damage even before decline of GFR, possibly making the kidneys to be more susceptible to damage by contrast material.

With univariate regression analysis of data in this study, urinary ACR, HbA1c and number of vessels affected was shown to be risk factors for occurrence of CIN after use of contrast, but with multivariate analysis, only urinary ACR and $\mathrm{HbA1c}$ was shown to be an independent risk factors for CIN. Other studies confirmed that pre-contrast GFR, urinary $\mathrm{ACR}^{\left({ }^{(19)}\right.}$, anemia, heart failure ${ }^{(23)}$ dehydration ${ }^{(24)}$ and HbA1c ${ }^{(25)}$ as independent risk factors for CIN. All of the above data further signifies the additive and cumulative effects of several risk factors in the development of contrast-induced nephropathy.

\section{CONCLUSION}

We concluded that among diabetic patients even with estimated GFR over 60, increased urinary albumin creatinine ratio could be a risk factor for the development of contrast-induced nephropathy post coronary angiography. In addition, the study highlighted the importance of proper control of blood sugar and the state of blood vessel. Further studies including larger number of patients may be needed to define the role of albuminuria in contrast-induced nephropathy.

\section{REFERENCES}

1. Rear R, Bell R, Hausenloy D (2016): Contrast-induced nephropathy following angiography and cardiac interventions. Heart, 102 (8): 638-648.

2. Mohamed R, Abdel-Aziz H, El Motteleb D et al. (2013): Effect of RAS inhibition on TGF- $\beta$, renal function and structure in experimentally induced diabetic hypertensive nephropathy rats. Biomedicine \& Pharmacotherapy, 67 (3): 209-214.

3. Mehran R, Aymong E, Nikolsky E et al. (2004): A simple risk score for prediction of contrast-induced nephropathy after percutaneous coronary intervention: development and initial validation. Journal of the American College of Cardiology, 44 (7): 1393-1399.

4. Perrin T, Descombes E, Cook S (2012): Contrastinduced nephropathy in invasive cardiology: incidence, pathophysiology, diagnosis, prevention and prognosis. Swiss Medical Weekly, 142: 13608-12.

5. Hossain M, Costanzo E, Cosentino J et al. (2018): Contrast-induced nephropathy: Pathophysiology, risk factors, and prevention. Saudi Journal of Kidney Diseases and Transplantation, 29 (1): 1-3.

6. Kapoor A, Gaur P (2017): Contrast-induced Nephropathy. Coronary Angioplasty. Evolved to Perfections, 291: 22-26.

7. Linkermann A, Heller J, Prókai Á et al. (2013): The RIP1-kinase inhibitor necrostatin-1 prevents osmotic nephrosis and contrast-induced AKI in mice. Journal of the American Society of Nephrology, 24 (10): 15451557.

8. Picken M, Dogan A (2015):. Pathologies of Renal and Systemic Intracellular Paraprotein Storage: Crystalopathies and Beyond Amyloid and Related Disorders. Springer, Pp: 179-194.

9. Ojo A (2014): Addressing the global burden of chronic kidney disease through clinical and translational research. Transactions of the American Clinical and Climatological Association, 125: 229-33.

10. Sany D, Refaat H, Elshahawy Y et al. (2014): Frequency and risk factors of contrast-induced nephropathy after cardiac catheterization in type II 
diabetic patients: a study among Egyptian patients. Renal Failure, 36 (2): 191-197.

11. Toprak O, Cirit M, Yesil M et al. (2006): Impact of diabetic and pre-diabetic state on development of contrast-induced nephropathy in patients with chronic kidney disease. Nephrology Dialysis Transplantation, 22 (3): 819-826.

12. Satirapoj B (2013): Nephropathy in diabetes Diabetes. Springer. $\quad$ Pp: 107-122. https://link. springer.com/chapter/10.1007/978-1-4614-5441-0_11

13. Kellum J, Sileanu F, Murugan $R$ et al. (2015): Classifying AKI by urine output versus serum creatinine level. Journal of the American Society of Nephrology, 26 (9): 2231-2238.

14. Wood S (2012): Contrast-induced nephropathy in critical care. Critical Care Nurse, 32 (6): 15-24.

15. Klima T, Christ A, Marana I et al. (2012): Sodium chloride vs. sodium bicarbonate for the prevention of contrast medium-induced nephropathy: a randomized controlled trial. European Heart Journal, 33 (16): 20712079.

16. Stacul F, van der Molen A, Reimer $P$ et al. (2011): Contrast induced nephropathy: updated ESUR contrast media safety committee guidelines. European Radiology, 21 (12): 2527-2541.

17. Han X, Zhang X, Liu K et al. (2018): Contrast-induced nephropathy in patients with diabetes mellitus between iso-and low-osmolar contrast media: A meta-analysis of full-text prospective, randomized controlled trials. PloS One, 13 (3): 0194330.

18. Tan H, Yi H, Zhao W et al. (2016): Intraglomerular crosstalk elaborately regulates podocyte injury and repair in diabetic patients: insights from a $3 \mathrm{D}$ multiscale modeling study. Oncotarget, 7 (45): 73130.

19. Ma C, Tang C, Qin Y et al. (2018): Relationship between Preoperative Urinary Microalbumin to Creatinine Ratio Level and Contrast-induced Nephropathy after Elective Coronary Angiography/Percutaneous Coronary Intervention. Angiol., 6 (214): 2-6.

20. Tao S, Wichmann J, Schoepf U et al. (2016): Contrastinduced nephropathy in CT: incidence, risk factors and strategies for prevention. European radiology, 26 (9): 3310-3318.

21. McCullough $P$ (2008): Contrast-induced acute kidney injury. Journal of the American College of Cardiology, 51 (15): 1419-1428.

22. Basile $D$, Anderson $M$, Sutton $T$ (2012): Pathophysiology of acute kidney injury. Comprehensive Physiology, 2: 1303-1353.

23. Isobe S, Yamada T, Yuba M et al. (2017): Relationship between pre-procedural microalbuminuria and renal functional changes after coronary computed tomography in diabetic patients. Journal of Cardiology, 69 (4): 666670.

24. Meloni M, Giurato L, Izzo V et al. (2017): Risk of contrast induced nephropathy in diabetic patients affected by critical limb ischemia and diabetic foot ulcers treated by percutaneous transluminal angioplasty of lower limbs. Diabetes/Metabolism Research and Reviews, 33 (3): 2866-73.

25. Bhatt S, Rajpal N, Rathi V et al. (2016): Contrast induced nephropathy with intravenous iodinated contrast media in routine diagnostic imaging: an initial experience in a tertiary care hospital. Radiology Research and Practice, Radiol Res Pract., 2016:8792984. 